\title{
In Memory of Professor Bruno Piombo
}

These series of special issues in memory of Professor Piombo have been co-edited by Luigi Garibaldi and Daniel Inman. A call for papers was issued in July 2003 and over 40 manuscripts were received and reviewed. The overwhelming response serves as testimony to the impact Bruno had on all of our lives.

Luigi and Dan

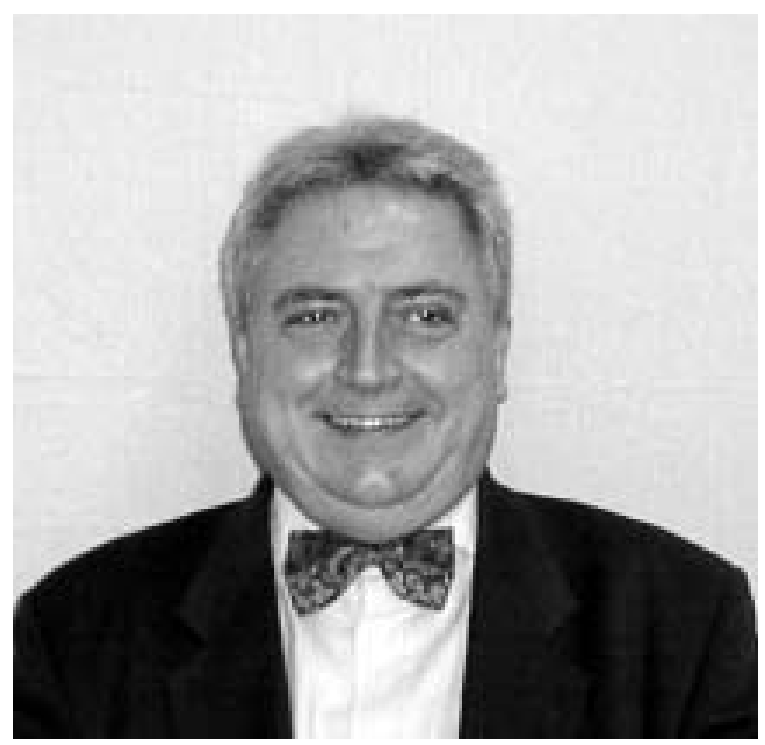

A dedication to Professor Bruno Piombo

Bruno Piombo was, above all, fantastic fun to be with. He was one of those special people who always put his friends first and enjoyed the company of people. Anyone who came into contact with Bruno will remember his kindness, his love of life, travel, good wine and good food, his wonderful jokes which, in true Bruno style, would make everyone laugh regardless of nationality. Bruno had the rare talent to make one feel good about themselves and always placed himself second, never wanting to be seen to be above his friends.

Yet, at the same time, he had an intellectual quality that often created thought provoking issues which helped him play an important role in the forward thinking of the Politecnico di Torino, demonstrating a vision of international collaboration that has had a significant positive impact on the Politecnico in relation to its standing.

Bruno was a true engineer, he loved to talk about how machines worked and his books Esercizi di Meccanica Applicata alle Macchine (1983) and Meccanica Applicata alle Macchine (in four volumes, 1991) are a reminder of his capability and his love of the subject. He was a dedicated dynamicist, with a special interest in Modal Analysis and was one of the first people at the Politecnico to introduce this topic into the engineering curriculum. He rarely missed the Modal Analysis Conferences (seen by Bruno as an opportunity to keep up to date with the subject and to meet old friends) and even organised an equivalent Conference in Florence to enhance the subject in his beloved Italy.

It would be remiss of me not to mention his daughter Ilaria and his Father whom he loved dearly and he frequently said how fortunate he was to have such a wonderful family. I know that Bruno also loved to visit Scotland, being a land of hills and mountains that were so close to his heart. 
I and my family, like all his friends, miss him and his 'make you feel good' presence.

I know that Bruno would consider it unnecessary to dedicate a Special Edition to him but this is nothing compared to what he brought in to my life and many, many others.

Ciao, Bruno - your dearest friend and colleague, Geof Tomlinson. 

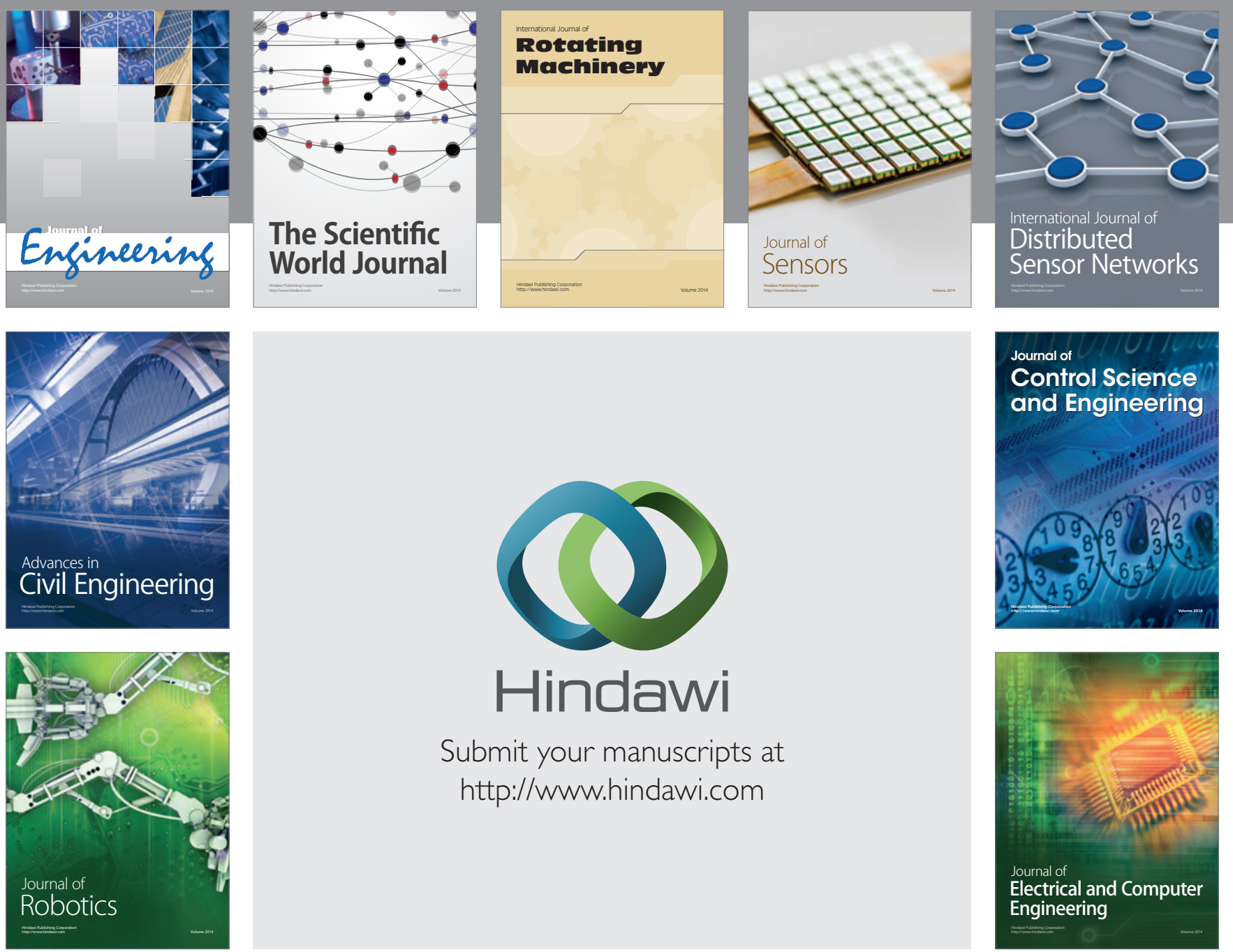

Submit your manuscripts at

http://www.hindawi.com
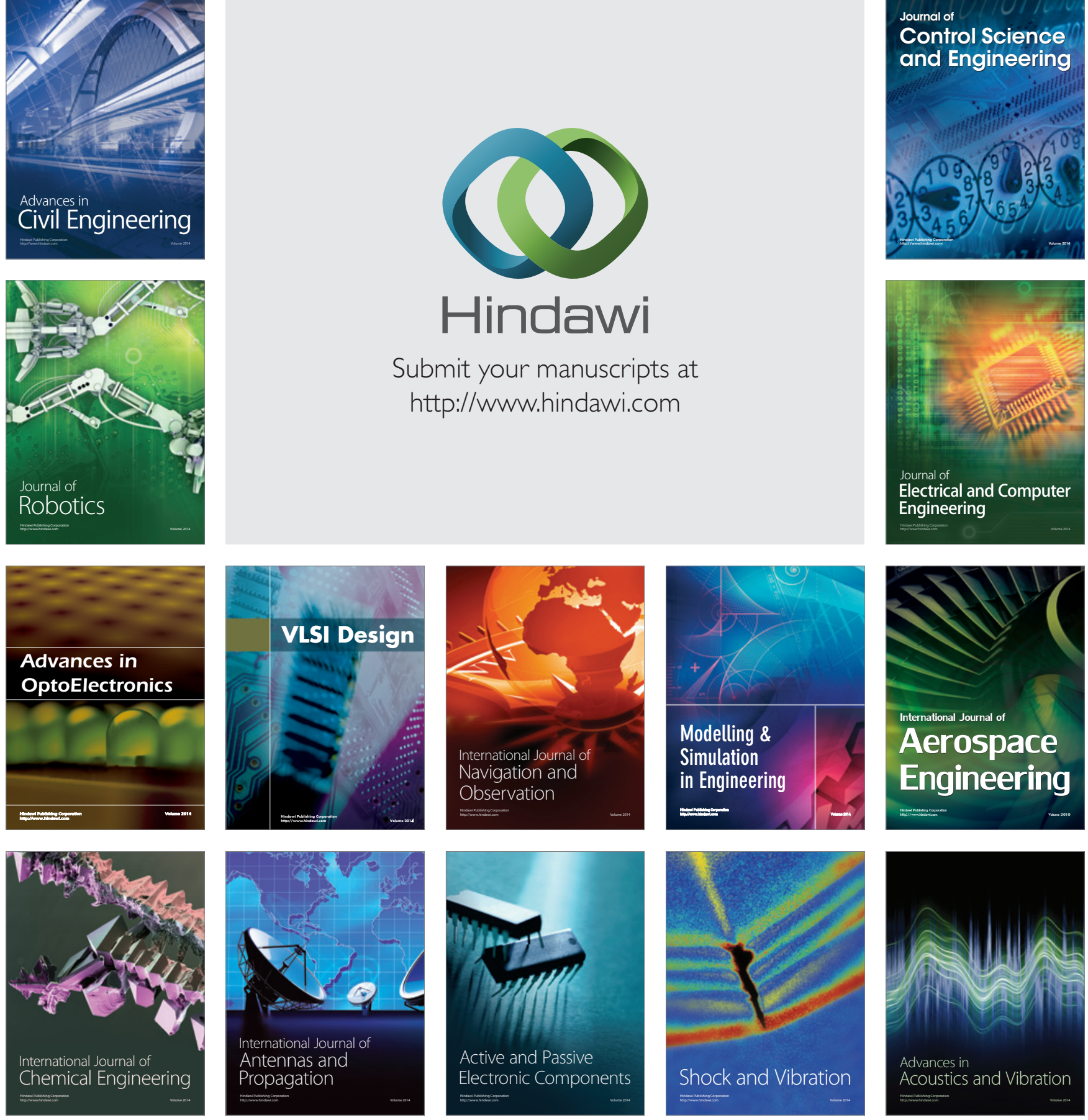